\title{
Reconstruction of Alar Lining and Nostril Base by Oral Mucosal Flap Based on Muscular Pedicle
}

\author{
Ayman Faraht ${ }^{1}$ MD, Osama Al-Shahat ${ }^{1}$ MD, Yasser Helmy ${ }^{1, *}$ MD and Ibrahim Eldosoky ${ }^{2}$ MD
}

\author{
*CorrespondingAuthor: \\ Yasser Helmy \\ dryasserhelmy@azhar.edu.eg \\ dryasserhelmy@gmail.com \\ Received for publication \\ November 15, 2019; Accepted \\ December 13, 2019; Published \\ on line January 20, 2020.
}

\section{Copyright 2020 The Authors}

published by Al-Azhar

University, Faculty of

Medicine, Cairo, Egypt. All

rights reserved. This an open-

access article distributed under

the legal terms, where it is

permissible to download and

share the work provided it is

properly cited. The work

cannot be changed in anyway

or used commercially.

doi:10.21608/aimj.2019.19565.1000

${ }^{I}$ Plastic \& Reconstructive

Surgery and Burn Department,

Faculty of Medicine, Al-Azhar

University Cairo, Egypt.

${ }^{2}$ Otorhinolaryngology

Department, Faculty of

Medicine, Al-Azhar University

Cairo, Egypt.

\begin{abstract}
Background: Nostril base and Alar wings are forming the major part of the nasal vestibule. This study proposes an innovative technique for functional restoration of alar lining and nostril base by myomucosal oral flap. It also evaluates the functional and aesthetic results of this technique after reconstruction of the nostril and alar subunits.

Patients and Methods: Case series study for the proposed technique. Study duration is one year, from January 2018 till 2019. Each patient followed for 6 months. Study setting is a university-based plastic surgery practice. Twelve Patients were complaining of unilateral nasal opening distortion due to scars. They included in consecutive sample. Proposed technique was operated on patients who underwent nostril base and Alar lining reconstruction. Objective morphological analysis is done for; the nasal width, mid-columella alar curvature distance, inter-axial angle and two nostril axis angles as well as the comparison of nasal pattern. Subjective analysis of patient's rating for breathing and aesthetic satisfaction level was reported.

Results: Functional and aesthetic outcomes were achieved from excellent to good. Breathing from the reconstructed nasal opening returned to the normal pre-scaring status in all cases.

Conclusion: To our knowledge, this article proposes a new innovative technique for functional reconstruction of Alar lining and nostril base by oral mucosal flap based on muscular pedicle. It could be a reliable, simple and straight forward technique.

Keywords: Functional; Reconstruction; Alar and Nostril subunits; muscular pedicle; oral mисоsa.
\end{abstract}

Disclosure: The authors have no financial interest to declare in relation to the content of this article. The Article Processing Charge was paid for by the authors.

Authorship: All authors have contributed to the article, however second author described the technique and the corresponding Author designed the study and created the figure that shows the morphological land marks for the base of the nose.

\section{INTRODUCTION}

Nasal opening is the beginning of nasal passage and upper respiratory system. Its vestibule is bounded medially by the columella, laterally by the Alar wings in each side and inferiorly by the nasal sill or the nostril. ${ }^{1,2}$ Any scarring, masses or distortions in the nasal entrance are result definitely in partial to complete obstruction of the airway passage. ${ }^{3}$ Local flap reconstruction procedures usually have a difficult technicality to restore the inner lining of the nose and each procedure has its own indication and complication. ${ }^{4,5,6}$

Morphological Anatomy: Nasal width is usually equal to the inter-canthal distance or beyond it by 2 mm. ${ }^{3,4}$ Three angles are join together to form the functional equilateral pyramid or triangle for the nasal base view. They are one inter-axial angle and two Nostril axis angles. ${ }^{1}$ Inter-axial angle is the result of meeting of the two nostril axes. The two nostril axis angles are the result of meeting of one nostril axis with the tangential sub-nasal line (sn) at alar fold or curvature level (ac). The land mark for the alar base insertion to the lip is a subalare (sbal). Each angle in this triangle is 60 degrees, they are two nostril-axis angle and one inter-axial angle. (Figure1) There are three common patterns of the nostril types according to the basal shape with ethnic variations. They are classified as; long (leptorrhine), narrow or medium (mesorrhine), and the short broad nose

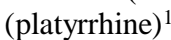




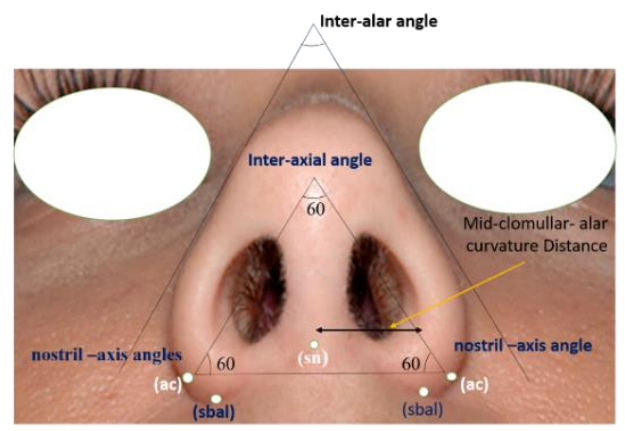

Fig. 1: shows the morphological land marks for the base of the nose.

In Symmetric Nostrils; the mid-columella to each alar curvature distance should be equal. This distance is usually distorted in case of presence of scars in nostril and alar lining. This article proposes a new innovative technique to achieve simple, matching and straight forward functional lining for the nostril and Ala. Study shows the functional outcome of Alar lining and Nostril base by oral myo-mucosal Flap.

\section{PATIENTS AND METHODS}

Twelve cases complaining of scarring and distortion of the nasal entrance at one side only, were included in this case series study. 8 males and 4 females are included, their average age is 27 years old. The cause of scarring was post burn complication in 6 cases, post-operative in 4 cases and post traumatic in 2 cases. Consents for surgery and photography were obtained from all patients as well as the approval of institutional ethical committee. Each patient was followed up for 6 months post-operative. Objective and subjective outcome analysis were done for all patients.

Objective analysis included pre-operative and postoperative measurements of; the nasal width, midcolumella alar curvature distance (MC-NC), interaxial angle (IAA) and two nostril axis angles (NAA) as well as the comparison of nasal pattern and review of complications. (Table1)

Subjective analysis was evaluated by questionnaire in form of patient's rating for breathing and aesthetic satisfaction level.

\section{Technique: (Figures 2-6)}

Under general anesthesia after sterilization and marking of the scar area, injection of adrenaline to saline solution 1:200000 is performed in withdrawal caution before injections. Then excision of the scar area in nostril or the lining Ala, is followed by measuring of the resultant defect in mm. Flap is drawn in the inner surface of the ipsilateral upper lip and designed in transversely oriented rectangle; its length is double the width and its width is equal to the recipient site defect. Usually the flap length is equal to the summation of patient's lateral incisor and canine width. Cutting is done through the mucosa in all sides of the flap as well as the muscles in tangential inclusion of orbicularis oris muscle (OO) in cut, but keeping the medial muscular pedicle fibers, 3-5 mm width or depth, which carries the random circulation of the flap. The muscular pedicle then dissected cautiously and kept attached to the bed of OO. The myo-mucosal flap then turned over through a penetration hole behind the course of superior labial artery. The hole is usually settled in the upper gingival sulcus, to reach the recipient defect in ease. Orientation and setting of the flap in the defect area is achieved, then simple stitching with interrupted 5/0 Vicryl sutures. Closure of donor site simply finished, with Gentle dressing.

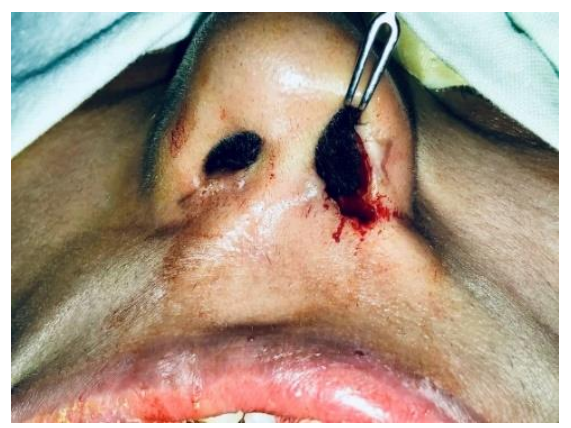

Fig. 2: shows defect's size and extension after scar removal.

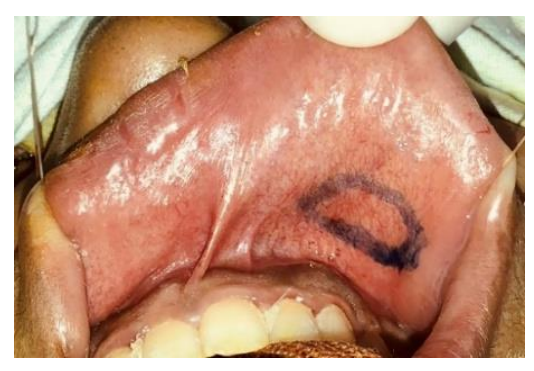

Fig. 3: shows oral myo-mucosal flap design.

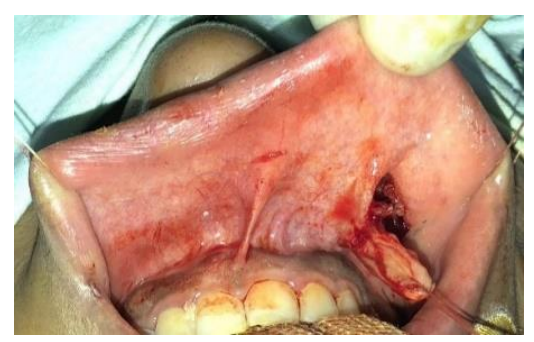

Fig. 4: shows the raised flap on random muscular pedicle.

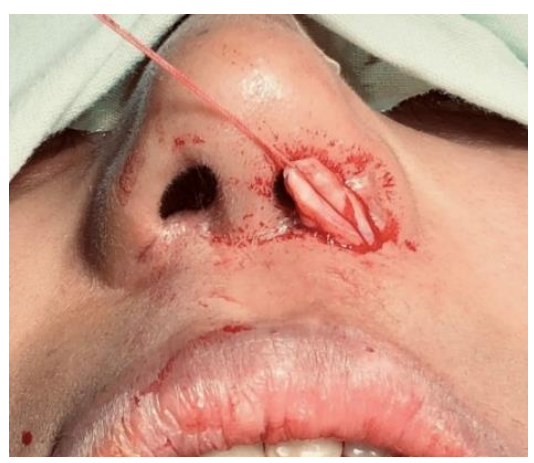

Fig. 5: shows orientation and setting of the flap. 


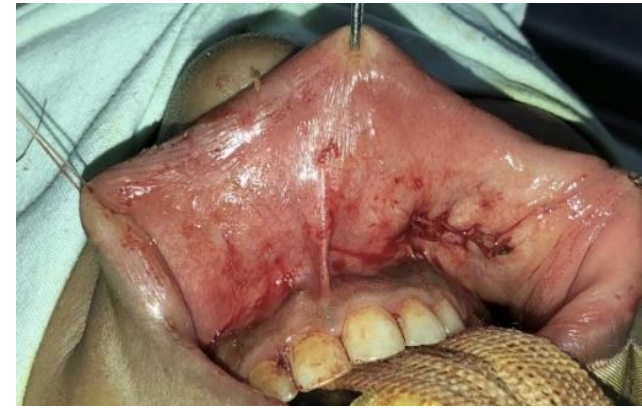

Fig. 6: shows simple closure of donor site by Vicryl $5 / 0$

\section{RESULTS}

Objective and subjective analysis of the 12 included patients in the study showed remarkable improvement in the pre-operative distorted midcolumella alar curvature distance. It increased from $4-6 \mathrm{~mm}$ in most cases while reached $12 \mathrm{~mm}$ in one case. All patients got post-operatively, exactly normal or near normal when compared with the other nostril. (Figure 7,8)

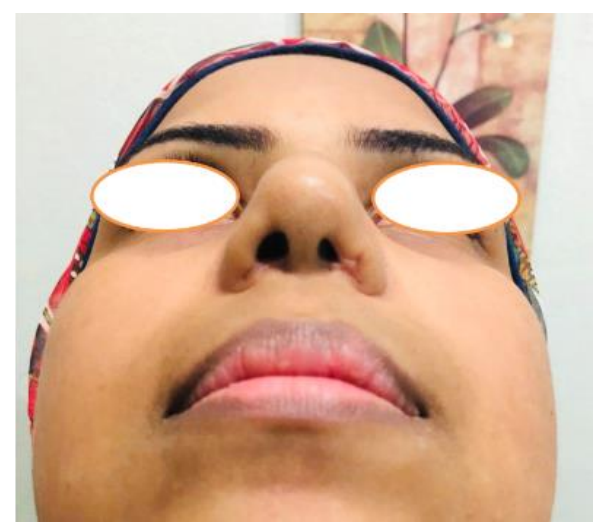

Fig. 7: shows pre-operative distortion of the morphology of the base of the nose

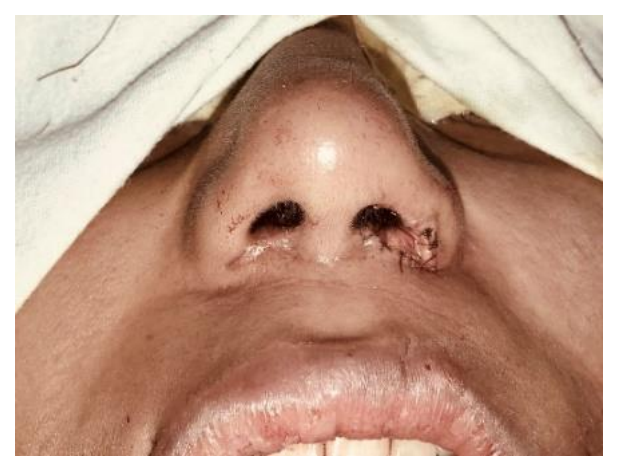

Fig. 8: Post-operative Restoration of alar and nostril sub-units and angles.
The inter-axial angle nearly has not changed, however the two nostril axis angles got equality and almost similarity after correction of the distorted nostril and /or Ala at the nasal vestibule. The 3 morphological angles got equality of 60 degrees in all patients.

The nasal width showed an improvement and increases few millimeters 2-4 towards the operated side in 3 cases and being in the normal values; equal to the inter-canthal distance or beyond by $2 \mathrm{~mm}$. Other 9 cases already have not pre-operative shortening of nasal width.

The comparison of nasal pattern of the pre and postoperative analysis has showed normal restoration of the normal shape, to be similar to the other side of the nose. In this study most of the nasal shape in basal view was narrow or medium (mesorrhine) in 10 cases and long (leptorrhine) in 2 cases.

After review of complications' records; there is no any reported major complications, away from lip swelling for couple of days. But actually no any hematoma, congestion, or necrosis of the flaps have been reported in the study. Subjective analysis in form of patient's rating for breathing and aesthetic satisfaction level were from excellent (Fully satisfied) to good (satisfied) in all cases of the study. They all have restored the pre-scarring function and almost aesthetically fully satisfied. Table 1 shows Demographics of the patients and post-operative functional outcome of Alar lining and Nostril base by oral myo-mucosal Flap. (Table 1,2)

\section{DISCUSSION}

Understanding of anatomical morphology and nasal subunit analysis are helpful in thinking of problem solving in reconstructive surgery practice..$^{1,2,3,4,7}$ The nasal opening patency and integrity of the nasal Ala and nostril sub-units are crucial points for normal breathing and aesthetic symmetry. Reconstruction of the Alar sub-unit and nostril usually staged in two operative setting and each technique carries its own complication. ${ }^{4,5,6}$ 


\begin{tabular}{|c|c|c|c|c|c|c|}
\hline Patient & Age & sex & $\begin{array}{c}\text { Cause of } \\
\text { deformity }\end{array}$ & $\begin{array}{c}\text { Shape of nasal } \\
\text { pattern }\end{array}$ & $\begin{array}{c}\text { Improvement } \\
\text { of Nasal width } \\
\text { in mm }\end{array}$ & $\begin{array}{c}\text { Improvement } \\
\text { of MC-NC } \\
\text { distance } \\
\text { in mm }\end{array}$ \\
\hline 1 & 26 & M & Post-surgical & mesorrhine & 0 & 4 \\
\hline 2 & 28 & M & Post-surgical & mesorrhine & 0 & 6 \\
\hline 3 & 32 & F & Post-surgical & mesorrhine & 2 & 6 \\
\hline 4 & 23 & M & Post-burn & leptorrhine & 0 & 8 \\
\hline 5 & 35 & F & Post traumatic & mesorrhine & 2 & 4 \\
\hline 6 & 35 & M & Post-burn & mesorrhine & 0 & 8 \\
\hline 7 & 40 & F & Post-burn & leptorrhine & 0 & 6 \\
\hline 8 & 32 & F & Post-surgical & mesorrhine & 0 & 5 \\
\hline 9 & 25 & M & Post-burn & mesorrhine & 0 & 7 \\
\hline 10 & 22 & M & Post-burn & mesorrhine & 4 & 6 \\
\hline 11 & 20 & M & Post traumatic & mesorrhine & 0 & 4 \\
\hline 12 & 19 & M & Post-burn & mesorrhine & 2 & 6 \\
\hline
\end{tabular}

Table 1: shows demographics of the patients and post-operative improvements in $\mathrm{mm}$.

\begin{tabular}{|c|c|c|c|c|c|}
\hline $\begin{array}{c}\text { Patie } \\
\text { nt }\end{array}$ & $\begin{array}{c}\text { IAA } \\
\text { Full } \\
\text { restoration to } \\
60 \text { degrees }\end{array}$ & $\begin{array}{c}\text { Full } \\
\text { restoration to } \\
60 \text { degrees } \\
\text { NAA }\end{array}$ & $\begin{array}{l}\text { Restoration of } \\
\text { nasal pattern }\end{array}$ & $\begin{array}{l}\text { Incidence/ type of } \\
\text { complication }\end{array}$ & Patient satisfaction \\
\hline 1 & + & + & + & - & Fully satisfied \\
\hline 2 & + & + & + & $\begin{array}{l}\text { Lip edema For } \\
\text { couple of days }\end{array}$ & Satisfied \\
\hline 3 & + & + & + & $\begin{array}{l}\text { Lip edema For } \\
\text { couple of days }\end{array}$ & Fully satisfied \\
\hline 4 & + & + & + & & Fully satisfied \\
\hline 5 & + & + & + & $\begin{array}{l}\text { Lip edema For } \\
\text { couple of days }\end{array}$ & Fully satisfied \\
\hline 6 & + & + & + & & Fully satisfied \\
\hline 7 & + & + & + & $\begin{array}{l}\text { Lip edema For } \\
\text { couple of days }\end{array}$ & Satisfied \\
\hline 8 & + & + & + & - & Fully satisfied \\
\hline 9 & + & + & + & - & Satisfied \\
\hline 10 & + & + & + & - & Satisfied \\
\hline 11 & + & + & + & $\begin{array}{l}\text { Lip edema For } \\
\text { couple of days }\end{array}$ & Satisfied \\
\hline 12 & + & + & + & - & Satisfied \\
\hline
\end{tabular}

Table 2: shows post-operative degrees of restoration and satisfactions after alar lining and nostril base reconstruction by oral myo-mucosal flap.

In this study the morphological measurements for assessment are; the nasal width, mid-columella alar curvature distance, inter-axial angle and two nostril axis angles. They all showed positive evidence by measurements in millimeters. This technique could provide simple thin lining of the Alar and nostril defects in contrary to the common practiced techniques. ${ }^{4,5,6}$ According to Zenga, ${ }^{8}$ Collin, ${ }^{10}$ et al, and Baker ${ }^{11}$ studies; the vestibular advancement flap provides coverage for roughly $10 \mathrm{~mm}$ of nasal lining. This proposed technique also could provide up to 12 $\mathrm{mm}$ width for nasal lining in simple one stage surgery.

Although visual analysis of the nasal base by experts could predict the improvement but we did measurements by ruler in millimeter to find out evident outcome data. ${ }^{12}$
The comparison of visual and photographic nasal patterns in this study showed a restoration to normal, almost like contralateral side of nasal opening in all cases. This surgical technique achieved nasal ventilation in a balanced pattern and has decreased nasal resistance for the airflow through the treated nasal opening, then increased the capacity of upper airway passage. In this study correction of external nasal valve stenosis is curative and this comes with the findings of Wang et al. ${ }^{13}$

Souter et al described the buccal mucosal flaps and their descriptions are designed on the labial mucosa of the upper buccal sulcus, based medially near the frenulum of the upper lip and extending laterally onto the mucosa of the cheek ${ }^{14}$. The pedicle in Souter's technique is only the mucosa and it is near to the frenulum so it is short. But this proposed technique depends on flattened muscular pedicle. This muscular 
pedicle allows the flap mobility and versatility and no need to be limited to the upper sulcus and could be harvested more far in the upper lip. This proposed flap technique doesn't has a risk of burying of the mucosa in deeper tissues like in Souter technique. The buried pedicle is a flitted viable fibers of the muscle orbicularis oris and it is normally placed in submucosal layer.

Incidence of fistula was higher in study conducted by Soutar and Elliot when the used superior sulcus oral mucosal flap to reconstruct the nose. ${ }^{14}$ However the incidence of complications in this study are very minor and just limited to lip swelling and tolerable post-operative pain. This could be explained by the use of splited muscle pedicle which may works as tight filling of the tunnel plus care in this study towards meticulous closure at donor as well as recipient sites of the flap. Study proposes simple reconstruction for simple defect without any need for superior labial artery flap as in study conducted by Turan et al. ${ }^{15}$ This study describes split muscle pedicles neither epithelial turn-in, ${ }^{16}$ nor extensive melolabial island flap ${ }^{17}$ as they are not indicated in such situations.

In this study there is no any patient experienced severe or annoying pain, although all of the 12 included patients underwent purely functional procedure, but in simpler way. This not come with observation published by Shekhar ${ }^{18}$ et al in 2019 when the patients have annoying postoperative pain records. However in Shekhar's study subjects underwent a full job rhinoplasty.

Subjective analysis in form of patient's rating for breathing and aesthetic satisfaction level showed excellent to good in all cases of the study. They all have restored the pre-scarring function and almost aesthetically fully satisfied. This technique is simple and has the advantage of single stage one day procedure. ${ }^{19}$

\section{CONCLUSION}

This study proposes a new innovative technique by using the oral mucosal flap based on muscular pedicle to reconstruct the Alar lining and nostril base defects. It provides a simple, versatile and reliable technique for nostril correction.

\section{REFERENCES}

1. Suhk J, Park J and Nguyen A. Nasal Analysis and Anatomy: Anthropometric Proportional Assessment in Asians-Aesthetic Balance from Forehead to Chin, Part I. Semin Plast Surg. 2015; 29 (4): 219-25. doi:10.1055/s-0035-1564817

2. Anderson $\mathrm{K}$, Henneberg $\mathrm{M}$ and Norris $\mathrm{R}$. Anatomy of the nasal profile. J Anat. 2008; 213 (2):210-6.

3. Cottle M. The Structure and Function of the Nasal Vestibule. Arch Otolaryngol.1955; 62 (2):17381 doi:10.1001/archotol.1955.03830020055011

4. Watanabe K. New ideas to improve the shape of the ala of the Oriental nose. Aesthetic Plast Surg. 1944; 18(4):337- 44.
5. Drisco B and Baker S. Reconstruction of Nasal Alar Defects. Arch Facial Plast Surg. 2001; 3 (2):91-99. Available at; https://jamanetwork.com/journals/jamafacialplast icsurgery/fullarticle/479841

6. Helmy Y, Ayman F and Mahmoud N, et al. Facial skin cancer reconstructive and cosmetic outcomes: Analysis with algorithm for its management. J Cosmet Dermatol. 2019; 8: 1-9. doi.org/10.1111/jocd.13121

7. Helmy Y. and Alfeky H. Plastic Surgery Interaction with Other Specialties; Scope of Specialty in Different Minds. Plast Surg Mod Tech. 2017; 1: 131-9. doi: 10.29011/25771701.100031

8. Zenga J. and Chi J. Reconstruction of the intranasal lining. Facial Plast Surg. 2017; 33(01):67-73.

9. Murakami C , Kriet J and Ierokomos A. Nasal reconstruction using the inferior turbinate mucosal flap. Arch Facial Plast Surg. 1999; 1(02):97-100.

10. Chen C, Ruchin P and John C. Comprehensive Algorithm for Nasal Ala Reconstruction: Utility of the Auricular Composite Graft. Surgery journal. 2018; 4 (2):55-61. doi:10.1055/s-00381639581

11. Baker S. Nasal lining flaps in contemporary reconstructive rhinoplasty. Facial Plast Surg. 1998; 14 (02):133-44.

12. Jacob K, Chelsey R, Michael D et al. Assessing Nasal Soft-Tissue Envelope Thickness for Rhinoplasty Normative Data and a Predictive Algorithm. JAMA Facial Plast Surg. published online September 5, 2019. doi:10.1001/jamafacial.2019.0715

13. Wang $\mathrm{T}$, Chen $\mathrm{D}$, Wang $\mathrm{P}$, et al. Investigation on the nasal airflow characteristics of anterior nasal cavity stenosis. Braz J Med Biol Res.2016; 49 (9):e5182. doi:10.1590/1414-431X20165182

14. Soutar D and Elliot D. Buccal mucosal flaps in nasal reconstruction. British Journal of Plastic Surgery. 1990; 43(6): 612-16

15. Turan A, Kostakoğlu N, Tuncel U. Reverse superior labial artery flap in reconstruction of nose and medial cheek defects. Ann Plast Surg. 2015; 74 (4):418-25. doi: 10.1097/SAP.0b013e31829d22a2

16. Park S, Cook T and Wang T. The epithelial 'turnin' flap in nasal reconstruction. Arch Otolaryngol Head Neck Surg. 1995;121(10):1122-7

17. Arden R and Miguel G. The subcutaneous melolabial island flap for nasal alar reconstruction: a clinical review with nuances in technique. Laryngoscope. 2012; 122 (8):1685-9. doi: 10.1002/lary.23377. Epub 2012 May 7

18. Shekhar K, Gadkaree, Shaye A, et al. Association between Pain and Patient Satisfaction after Rhinoplasty. JAMA Facial Plast Surg. 2019; Published online September 19, 2019. doi: 10.1001/jamafacial. 2019.0808.

19. Beneng K, Sproat $\mathrm{C}$ and Kwok J. Intraoral Surgical Removal of Submandibular Sialoliths as a Day Case Procedure: A Case Series of 72 Patients. Journal of Oral and Maxillofacial Surgery. 2019; 77 (9) e80 - e81. doi: https://doi.org/10.1016/j.joms.2019.06.10

(1) 